\title{
ANOTHER LOOK AT the CAPM In SOUTH AfRICA: the INFLUENCE OF BULL AND BEAR MARKETS
}

\author{
Ailie Charteris \\ University of KwaZulu-Natal \\ charterisa@ukzn.ac.za
}

Received: April 2013

Accepted: March 2014

\begin{abstract}
Several studies of the Capital Asset Pricing Model (CAPM) in South Africa find that beta cannot explain returns. However, these studies do not consider the effect of bull and bear markets, yet over the period 1995-2009, excess market returns were positive in only 98 of 180 months. The influence of market conditions on the risk-return relationship is examined internationally by evaluating the conditional risk-return relationship where risk premiums are allowed to vary in bull and bear markets, and the dual-beta CAPM, which allows for the sensitivity of an asset to the market to vary under the two economic states. In this study, the ability of these two models to explain returns on South African shares is compared to the CAPM using the Fama and MacBeth (1973) and panel data approaches. The dual-beta model is found to be more successful than either the conditional relation or CAPM, as bulland bear-market betas differ; but the estimates of the risk premiums in this model are significant only after adjusting for market segmentation. The findings thus indicate that asset-pricing models with time-varying risk should be the focus of future asset-pricing tests.
\end{abstract}

Keywords

Conditional CAPM, dual-beta CAPM, market returns, beta, Johannesburg Stock Exchange, bull and bear markets, emerging markets.

Ms A Charteris is a lecturer at the School of Accounting, Economics and Finance, University of KwaZulu-Natal, South Africa. 


\section{INTRODUCTION}

The frequently cited 'first principle of finance' is that higher risk should be compensated for by higher returns. The CAPM depicts the equilibrium risk-return relationship, showing that the expected return on a risky security or portfolio is the sum of the return on the risk-free asset and a premium for bearing non-diversifiable risk, as any firm-specific risk is assumed to have been eliminated by the investor through diversification (Sollis, 2012:115). This relationship is shown as:

$$
E\left(R_{i}\right)=E\left(R_{f}\right)+\beta_{m, i}\left[E\left(R_{m}\right)-E\left(R_{f}\right)\right]
$$

where: $E\left(R_{i}\right)$ is the expected return on asset $i, E\left(R_{f}\right)$ is the expected return on the risk-free asset, $\beta_{m, i}$ is the measure of systematic risk of asset $i$ and $E\left(R_{m}\right)$ is the expected return on the market portfolio (Sollis, 2012:115).

Since the development of the CAPM, it has become the most widely used model in practice for estimating the cost of equity, both internationally and in South Africa (Correia \& Cramer, 2008). However, Van Rensburg and Robertson (2003), Strugnell, Gilbert and Kruger (2011) and Ward and Muller (2012) document overwhelming evidence against its suitability. Most notably, these three studies find a negative relationship between beta and returns, which contradicts the theory that risk should be commensurate with returns. The finding of evidence disputing the validity of the CAPM is not unique to the South African market. In their seminal paper, Fama and French (1992) found that beta was not able to explain the cross-section of share returns in the United States (US) and that the relationship between risk and return was flat.

A number of explanations have been proposed to account for the inability of beta to explain returns, one of which is that while the CAPM is a theory based on expected returns, in tests of the model realised returns are used (Pettengill, Sundaram \& Mathur, 1995). Accordingly, an adjustment must be made for this, as it is plausible that returns of the market portfolio may be lower than the risk-free rate and, under these conditions, returns should be negatively related to risk. This conditional relationship between risk and return has proven to be very successful in explaining returns in the US (such as Petengill et al., 1995) and other markets (see for example Fletcher, 1997, and Morelli, 2007, for the United Kingdom (UK) and Vosilov and Bergstrom, date?, for Sweden). In contrast, in a recent study, Limberis (2012) found that in South Africa, irrespective of whether up or down market returns are examined, beta is unable to explain returns.

A similar argument rests on the basis that beta may vary during bull and bear markets; this is known as the dual-beta CAPM, originally proposed by Fabozzi and Francis (1977). In contrast to the conditional relationship, which allows for varying risk premiums in market upturns and downturns, the dual-beta CAPM estimates two separate betas for these states, suggesting that shares may be more highly correlated with the market during upturns than downturns or vice versa. Although initially not particularly successful, more recently this model has been found to be able to account for several of the shortcomings of the traditional CAPM in the US and other markets.

Identifying a suitable replacement for the CAPM to estimate the cost of equity is of paramount importance, given the numerous applications in which a cost of equity estimate is required. If the market return was seldom below the risk-free rate, then the effects of allowing for varying market conditions would be negligible; however, the South African market is highly volatile and 
hence excess market returns are frequently negative. To this author's knowledge, the recent study of Limberis (2012) is the only research to have considered the influence of market states on the CAPM risk-return relationship of South African securities. However, his study considers these issues only as a small component of the research, with the principal focus on the measure of risk as opposed to the relative explanatory power of the models. Accordingly, he does not test the conditional and dual-beta forms of the CAPM, as defined in the literature. Thus the purpose of this study is to explicitly examine whether the conditional relationship implied by the CAPM or the dual-beta CAPM are better able to explain returns on South African shares than the traditional CAPM.

\section{LITERATURE REVIEW}

\subsection{The failure of the CAPM}

Initial tests of the validity of the CAPM found weak support for the central tenet of the model that the relationship between risk and return is positive and linear (Black, Jensen \& Scholes, 1972; Fama \& MacBeth, 1973). However, in the late 1970s and early 1980s a body of evidence began to emerge highlighting several pitfalls of the model, in that beta could not explain the differences in returns across portfolios formed on the basis of price-to-earnings $(P / E)$ and book-to-market (B/M) ratios and size (Basu, 1977; Banz, 1981). Fama and French (1992) synthesised the findings of these previous studies and confirmed that the CAPM was unable to explain the differences in returns across shares sorted on the basis of size, value and historical betas. This finding is not unique to the US market, as Fletcher (1997 \& 2000) found little relationship between beta and returns in the UK and international markets respectively.

A number of explanations have been proposed to account for the poor performance of the model. The first of these is that beta is still an important determinant of returns, but it does not fully incorporate all risk factors (Fama \& French, 1993). Secondly, data discrepancies such as survivorship bias, data snooping, and the use of realised and unexpected returns may account for the phenomena observed (Lo \& MacKinlay, 1990; Pettengill et al. 1995), and finally that the traditional model does not allow for the variation in systematic risk over time (Bhardwaj \& Brooks, 1993).

In response to the argument that the CAPM does not include all relevant risk factors, Fama and French (1993) proposed a three-factor model, where the factors are the market return, the return on a 'size' portfolio, and the return on a 'value' portfolio. This model has been shown to perform well in describing returns, with the size and value portfolios being viewed as proxies for unobservable risk factors. The major criticism of this model, however, lies in its lack of theoretical underpinning, as it is entirely motivated by empirical findings and accordingly lacks intuitive appeal (Basiewicz \& Auret, 2010).

As far as the data discrepancies are concerned, many of these have been refuted by further studies: in particular, the issue of survivorship bias has been discarded (Haugen \& Baker, 1996). However, others have withstood further investigation and hence provide valuable information for the future of asset pricing. In this regard, the argument of Pettengill et al. (1995) has found strong support in lieu of its intuitive appeal that while the ex-ante risk premium is always positive, the ex-post returns to the market can be negative, which gives rise to a conditional relationship between risk and return where the relationship is conditional upon the market conditions. 
The third explanation is that beta does not take into consideration the dynamic and constantly changing environment, as it is possible that risk may vary as market conditions change. That is, the risk of each share may fluctuate such that a share may be more highly correlated with the market during up markets than down markets (Bhardwaj \& Brooks, 1993). The dual-beta CAPM was one of the first models developed within this framework, where beta is allowed to vary depending on up and down market conditions. More recently, the idea of a time-varying beta has been expanded substantially as scholars seek to assess how the flow of information affects beta. However, these specifications fall beyond the scope of this study, as the focus is limited to the impact of up- and down-market conditions on the risk-return relationship. If the dual-beta model is successful, it will suggest further exploration of time-varying risk estimates for the South African market.

\subsection{The conditional relation between Beta and realised returns}

Pettengill et al. (1995) suggest that the flat relationship between risk and return may be due to the fact that the CAPM is an expectational model, but realised and unexpected returns are used in these studies; thus they argue that the validity of the CAPM has not been explicitly evaluated in previous tests. The market portfolio is a risky portfolio of securities, and thus by definition the expected return must be greater than the risk-free rate to compensate investors for the greater risk associated with holding the market portfolio. Therefore, the expected return for a risky security must be positively related to its beta, as reflected in equation l (Ho, Strange \& Piesse, 2006). To test whether this relationship holds in practice, scholars regress realised return of securities against the estimated betas as follows:

$$
\bar{R}_{i}=\gamma_{0}+\gamma_{1} \hat{\beta}_{i}+\eta_{i}
$$

where: $\bar{R}_{i}$ is the average excess return on share i over a period in time and $\hat{\beta}_{i}$ is the estimated beta of the share. $\gamma_{0}$ and $\gamma_{1}$ are the estimated coefficients and represent the difference between the minimum return required by investors and the risk-free proxy yield and the market risk premium respectively. If the CAPM holds, $\gamma_{1}$ should be positive and significant, as it represents the market risk premium. The beta of the share is estimated as follows:

$$
R_{i}-R_{f}=\alpha_{i}+\beta_{i}\left(R_{m}-R_{f}\right)+\varepsilon_{i}
$$

where: where $R_{t}$ is the portfolio return, $R_{f}$ is the risk-free rate and $R_{m t}$ is the return on the market portfolio in each month.

If the excess market return is guaranteed to always be positive it is logical to infer that no rational investor would hold the risk-free asset. However, the market risk premium is not known with absolute certainty, which implies that there is a non-zero probability that the risk premium can be negative. Therefore, the relationship between realised returns and beta is conditional on the relationship between the realised market return and the risk-free rate. Consequently, this implies a positive relationship between beta and returns when the risk premium is positive (i.e. if $\left(R_{m}-R_{f}\right)>0$, then $\left(R_{i}-R_{f}\right)$ is positively related to beta) and a negative relationship when the risk premium is negative (i.e. if $\left(R_{m}-R_{f}\right)<0$, then $\left(R_{i}-R_{f}\right)$ is negatively related to beta).

In testing the CAPM through equation 2, this conditional relationship is not captured. Hence, Pettengil et al. (1995:107) suggested the following, more accurate test: 


$$
\bar{R}_{i}=\gamma_{0}+\gamma_{1} \delta \hat{\beta}_{i}+\gamma_{2}(1-\delta) \hat{\beta}_{i}+\eta_{i}
$$

where: $\delta$ is equal to one if the risk premium is positive, and zero if the risk premium is negative. From a theoretical perspective, $\gamma_{1}$ should be positive and significant, as it reflects the estimated market risk premium in periods where the market risk premium is positive, whereas $\gamma_{2}$ should be negative to capture the negative relationship between risk and return when the market risk premium is negative.

Using this framework Petengill et al. (1995) found a consistent and significant relationship between beta and returns in the U.S. from 1926 to 1990; that is, a positive risk premium was obtained for bull markets and a negative premium for bear markets. Moreover, the risk premiums were found to be approximately equal across the two states. Fletcher (1997) and Morelli (2007) also obtained evidence in support of distinct risk premiums in up and down markets in the UK. However, Fletcher (1997) found a larger risk premium in the down market than in the up market, suggesting that investors require greater compensation for losses than for gains. Ho et al. (2007) attribute this finding to greater investor overreaction in bear markets. Evidence in support of the conditional relation in developed markets has also been documented by Vosilov and Bergstrom (2010) for the Stockholm Stock Exchange and Elsas, El Shaer and Theissen (2003) for Germany, with both studies confirming that the up- and down-market premiums were reasonably symmetrical.

The lack of success of the CAPM in developing countries in particular has sparked numerous studies on the conditional relation between risk and return. For example, Lam (2001) and Ho et al. (2007) found a positive relationship in up markets and a negative relationship between beta and returns in down markets. Both studies found the risk premiums to be asymmetric, as the negative relationship was steeper. This may account for the finding of a strong negative relationship between risk and return when the unconditional relationship was examined.

The conditional relation has also been tested by Hodoshima, Garza-Go'mez and Kunimura (2000) in Japan, Sandoval and Saens (2004) for four markets in Latin America, Zhang and Wilborg (2010) in six emerging European markets and Choi and Fu (2005) in New Zealand. These studies all found that beta is only a sufficient measure of risk after taking into consideration market conditions; however, there was no similarity with regard to the symmetry of the risk premiums. The Japanese and European emerging market evidence supported the conclusion that the risk premiums were symmetrical in up and down markets, whereas Sandoval and Saens (2004) found evidence to the contrary in three of the four Latin American markets, with the down market risk premium exceeding the up market risk premium, a similar finding to that of Choi and Fu (2005) in New Zealand.

The evidence thus seems to point quite strongly to the fact that the conditional relationship between risk and return holds irrespective of whether the market is developed or developing. However, there is a greater likelihood that the down market risk premium is larger than the up market premium in developing markets, suggesting that the market is more sensitive to bear runs than bull runs. Such a finding is not surprising in light of the fact that many firms in developing countries may be less well-equipped to survive and re-emerge after a major market downturn and hence investors require a greater premium for this possibility.

The only study which has attempted to consider this relationship between risk and return is that of Limberis (2012). His findings indicate that the relationship between beta and returns is insignificant irrespective of whether only up markets or only down markets are considered; but he did not examine the up and down market conditions jointly. Although Limberis (2012) finds an 
insignificant unconditional relationship between beta and returns, it is positive, whereas Strugnell et al. (2011) documented a negative relationship over an almost identical 10-year horizon. Moreover, in the down market, the estimated risk premium was found to be positive, rather than negative, as would be expected based on the realised relationship between risk and return. These findings are certainly surprising and warrant further analysis.

\subsection{The Dual-Beta Asset-Pricing Model}

The dual-beta model incorporates varying risk over time between bull and bear markets, which seem to be strongly related to the troughs and peaks of the business cycle (Bhardwaj \& Brooks, 1993:272). Thus, the model allows for a share to respond differently to the market in upturns and downturns. The dual-beta model initially developed by Fabozzi and Francis (1977) and later revisited by Bhardwaj and Brooks (1993) and Howton and Peterson (1998) requires a different specification for the estimation of the beta of a security, as two betas are now estimated, as evidenced in equation 5 . This model can then be tested in the same framework as the static and conditional models, as shown in equation 6 . As is clear from this process, the inclusion of two betas in the test equation gives rise to two estimates of the market risk premium - one which reflects the risk-return relation in bull runs and the other the risk-return relation in bear runs. Thus, the similarity between the dual-beta and conditional relationship lies in the estimation of two distinct risk premiums depending on the state of the market.

$$
\begin{gathered}
R_{p t}=\alpha_{u p} \delta+\alpha_{\text {down }}(1-\delta)+\beta_{u p} \delta R_{m t}+\beta_{\text {down }}(1-\delta) R_{m t}+\varepsilon_{t} \\
\bar{R}_{p t}=\gamma_{0}+\gamma_{1} \hat{\beta}_{\text {up }}+\gamma_{2} \hat{\beta}_{\text {down }}+\eta_{p}
\end{gathered}
$$

where: $\beta_{u p}$ and $\beta_{\text {down }}$ are the betas in up and down markets respectively.

Fabozzi and Francis (1977) tested the equality of bull- and bear-market betas in the US and found that they did not differ significantly; thus lending support to the traditional CAPM. However, Bhardwaj and Brooks (1993) re-examined the ability of the dual-beta CAPM to explain US share returns using portfolios formed on the basis of size. All the portfolios demonstrated negative (positive) average returns in bear (bull) months, with these patterns conforming to the conditional relationship implied by the CAPM. The bull- and bear-market betas were significantly different across all the portfolios, with the betas of small firms larger in bull than bear months, while the opposite was true for large firms (Bhardwaj \& Brooks, 1993). Thus, these results assisted in explaining the fact that in bear months small firms underperformed large firms but outperformed large firms in bull months. This study thus provides strong support in favour of the dual-beta model.

Howton and Peterson (1998) expanded the study of Bhardwaj and Brooks (1993) to include cross-sectional tests of the model. They confirmed the findings of Fama and French (1992) that beta was insignificant in explaining returns, even when used in conjunction with other variables such as size and the B/M ratio. However, when the dual-beta model was used there was a significant relationship between beta and returns, even with other variables included.

Woodward and Anderson (2009) examined the suitability of the dual-beta CAPM in the Australian market, using a trend-based definition of bull and bear markets, and found that upand down-market betas differ significantly, with bull markets persisting for longer periods than bear markets. From the perspective of developing markets, Bhaduri and Durai (2006) and 
Suntraruk (2008) examined the validity of the dual-beta CAPM in India and Thailand respectively. Both studies found little evidence in support of the dual-beta specification, as the bull-and bear-market betas were not found to differ significantly.

Choi and Fu (2005) also tested the dual-beta CAPM in New Zealand, performing cross-sectional tests in the spirit of Howton and Peterson (1998). Their results reveal an insignificant risk premium in up markets but a significant negative risk premium associated with down markets. Their results are identical to Hodoshima et al. (2000), who also reviewed the dual-beta CAPM in their analysis of Japan, thus suggesting that in these markets the dual-beta model provides a better fit when market returns are negative.

These findings for emerging markets tie in directly with the work of Estrada (2000). He argued that the current evidence indicates that beta is not related to returns in emerging markets, whereas in developed markets, there is some evidence to suggest that beta is still an appropriate measurement, but that it needs to be supplemented with other factors. He argues that investors are far more concerned about downside risk than upside potential and thus postulates that the risk measure used by investors should reflect downside risk only. Accordingly, he proposes the use of a Downside CAPM (DCAPM), which closely mirrors the dualbeta CAPM but without the up-market beta. The analysis of Estrada (2000) provides strong evidence in favour of the downside measurement of beta. However, prior to limiting the analysis to only downside movements, it is of value to consider the possibility that returns may still be associated with risk in up states as well, as per previous studies.

Pettengill, Sundaram and Mathur (2002) compared the dual-beta model to the conditional relationship, including $B / M$ and size as factors in their comparison. Pettengill et al. (2002:125) found that the conditional relationship between risk and return was sufficient and "bull and bear market betas are not a necessary condition to find a significant relationship between risk and return". Likewise, Faff (2001) examined the usefulness of both specifications for the Australian market. His results revealed that only six of 24 industry portfolios exhibited bull and bear betas which were statistically different. Additionally, he found the bear-market beta to be significantly greater than the bull-market beta for five of these portfolios. Although these results were not particularly significant, the findings of the cross-sectional analysis revealed that both the up-market and down-market betas were priced factors. Faff (2001) also established that there was a consistent and significant relationship between beta and returns when market conditions were considered. Thus, Faff (2001) illustrated that allowing for both varying market risk premiums and varying measures of systematic risk under different market conditions could not be rejected for the Australian market.

\section{DATA AND METHODOLOGY}

Despite the success of the conditional relationship between beta and returns internationally, only Limberis (2012) has briefly reviewed the model for the South African market, with findings that contrast with international results. This study thus seeks to assess the validity of the findings of Limberis (2012) by using a longer period of analysis, an alternative sorting procedure and the same test equation as applied in the international literature. Moreover, this study also extends the analysis to review the dual-beta CAPM, which has not been examined for Johannesburg Stock Exchange (JSE)-listed shares, to assess whether risk measures may actually vary in bull and bear markets. Thus, the purpose of this study is to expand the research on assetpricing models to determine whether either the conditional relationship or dual-beta CAPM is 
preferable to the traditional CAPM. In order to provide a basis of comparison for the conditional and dual-beta models, the CAPM was also tested.

The most common approach to asset-pricing tests is the Fama and MacBeth (1973) two-pass regression (hereafter the FM approach) and this was adopted in this study. The value of this approach is that it enables each model to be estimated and then compared on the basis of adjusted R-squared and the extent to which the estimated parameters conform to theory.

The first step in this process to test the CAPM was to estimate betas for each portfolio as per equation 3. Beta estimates were obtained for each month for each portfolio using the immediately preceding five years of observations and rolling the window forward for each beta estimate, as this allows for variation in the beta parameters over time. This yields beta estimates for each portfolio for each month from January 2000 to December 2009. The second stage of the FM approach entailed estimating a cross-sectional regression, as per equation 2, for every month from January 2000 to December 2009. The coefficient estimates were then averaged over the months. The disadvantage of this second stage is that over shorter estimation horizons (such as in this study) the variation of parameter estimates can be quite large, therefore resulting in insignificant coefficients. Accordingly, some studies have used a pooled approach, which involves combining the time-series observations for each portfolio (essentially stacking them) and then estimating the regression over the entire period rather than each month, as displayed in equation 7. This method is based on the assumption that the relationship between the variables (as captured by the slope coefficient) is constant over time. In light of the benefits of this approach, this method was also used in this study to assess the robustness of the findings from the FM approach.

$$
\bar{R}_{p t}=\gamma_{0}+\gamma_{1} \hat{\beta}_{p t}+\eta_{p t}
$$

where $\bar{R}_{p t}$ is the average return of each portfolio over the previous sixty months for each month and $\hat{\beta}_{p t}$ is the estimated beta of each portfolio for each month in the sample. The shortcoming of simply pooling the observations is that it assumes that the average value of the intercepts is also constant over time and across portfolios (Asteriou \& Hall, 2011:417). Accordingly, two alternative approaches were adopted under the framework of panel data estimation techniques, which allow for a less restrictive assumption. The first of these is the fixed-effects method, where the intercept is treated as portfolio-specific and/or time-specific, and thus can vary across each portfolio and each period. In contrast, with the second approach, known as random effects, the intercepts are also allowed to vary and are not treated as constants, but rather as random parameters that emanate from a common intercept (Asteriou \& Hall, 2008:418).

For the purposes of this study, fixed effects were deemed more appropriate than random effects, as it is unlikely that the intercept measures, in capturing the minimum return required by investors above the risk-free rate, are unlikely to come from the same common source. Moreover, time period fixed effects were imposed rather than cross-sectional, as this allows for the intercept estimate to vary across time, which makes sense, as it captures the excess minimum return (above the risk-free rate proxy used) required by investors from investing which may vary over time. In contrast, if cross-sectional fixed effects were imposed, this allows for the intercept to vary across each portfolio and, according to Esterer and Shroder (2011), in the context of asset-pricing tests, this is likely to capture other underlying risk factors common to the portfolios. However, given the purpose of testing the models under review, it is of value to ascertain how they capture the risk-return relationship and not the effects of other underlying risk factors. Employing the fixed-effects approach to estimate the model will still give rise to 
the same parameters as per equation 7 , and the R-squared of the model can then be compared to the other relations tested.

The conditional risk-return relationship was also estimated using the FM and panel approaches; the only difference between this and the CAPM test is the form of the cross-sectional regression, which distinguishes between up-and down-market conditions. Equation 4 was used as the test equation for the FM approach, while the panel data equation is specified in equation 8 below.

$$
\bar{R}_{p t}=\gamma_{0}+\gamma_{1} \delta \hat{\beta}_{p t}+\gamma_{2}(1-\delta) \hat{\beta}_{p t}+\eta_{p t}
$$

If the conditional relation holds, $\gamma_{1}$ should be positive and $\gamma_{2}$ negative. Moreover, the estimated risk premiums should be symmetrical in bull and bear markets, and this was ascertained using an F-Test (or Wald test) of the equality of the coefficients (Asteriou and Hall, 2011:80).

The dual-beta model, in contrast to other tests of the validity of the CAPM, is traditionally examined in a time-series framework (as per the first-pass regression approach of FM), as shown in equation 5 . The test of the validity of the dual-beta model lies in the equality of the up- and down-market betas and thus this was assessed with the use of a t-test. In order to establish whether a particular month is bullish or bearish several definitions were suggested by Fabozzi and Francis (1977); the most commonly employed in practice being 'up and down returns', where the divide is drawn based on whether the returns are positive or negative and the 'median return' where the median is used as the cut-off value in distinguishing the up and down values. The 'up and down returns' definition was used, but the analysis was repeated with the 'median return' definition and no notable differences in the results were observed.

Furthermore, the dual-beta model has been tested in a cross-sectional framework, as per equation 6 based on the FM method, and was used in this study. This was combined with a panel analysis, as per equation 9 .

$$
\bar{R}_{p t}=\gamma_{0}+\gamma_{1} \hat{\beta}_{u p}+\gamma_{2} \hat{\beta}_{\text {down }}+\eta_{p}
$$

Similarly to the conditional model, $\gamma_{1}$ is expected to be positive and $\gamma_{2}$ negative if the dual-beta holds, with the coefficients approximately symmetrical.

Once the three models were estimated, the coefficients were assessed to ascertain whether they were significant and had the correct signs, in accordance with theory. Further to this, to compare the extent to which each of the specifications is able to explain returns on JSE-listed shares, the success of each model was assessed using the adjusted R-squared measure.

To test these models, monthly closing share prices and annual dividend yields were obtained from the JSE statistics and records department for all shares listed on the main board for the period January 1995 to December 2009. The sample consisted of all ordinary shares listed on the main board of the JSE, adjusted for newly listed, delisted and suspended shares each year so as to avoid survivorship bias. Similarly to Van Rensburg and Robertson (2003), a thin-trading filter was applied to remove all those shares that did not trade at least once during the month. This is imperative, as beta estimates for less actively traded shares are likely to be unreliable and the returns on shares that are infrequently traded tend not to be normally distributed, an implicit assumption of the analysis.

The number of shares that were included in the sample in each year is shown in FIGURE 1, as is a comparison to the total number of shares listed over the period. The total number of JSE listings increased from 639 in 1995 to 668 in 1999 in line with international markets, before falling 
dramatically to a low of 373 in 2005. This was followed by a slight increase from 2006 to 2008, coinciding with a boom period in the South African economy, before falling again in 2009. The fact that the number of shares declined by over $40 \%$ over the sample period impacts upon this study, unlike other country analyses where an increasing trend in the number of shares listed has generally been evident (for example, Australia and India). In their test of the CAPM in South Africa, Ward and Muller (2012) placed a cap on the number of shares used so as to include only the largest 160 shares listed in each year. Their findings regarding the risk-return relationship are consistent with previous research in South Africa, which allowed the number of shares included in the sample to vary year-by-year; thus, there is evidence to suggest that the impact of dramatically declining numbers of shares in the sample should be small.

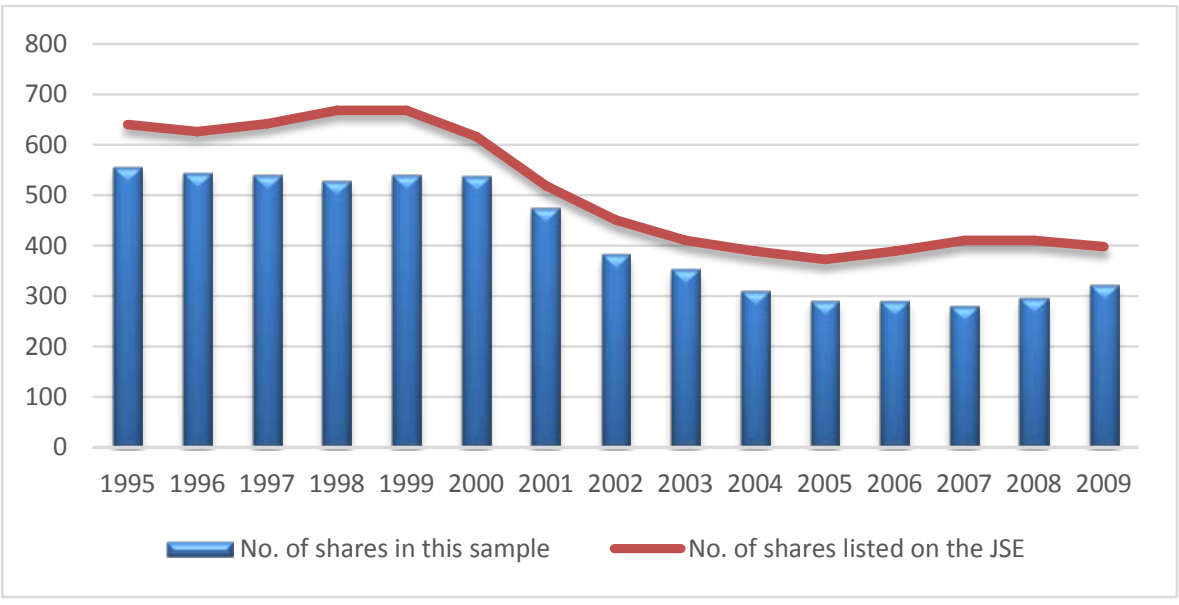

\section{FIGURE 1: JSE Listings and the Number of Shares in this Sample}

\section{Source: World Federation of Exchanges, 2013 and own calculations}

Monthly security returns were computed as the sum of the capital gain yield and one-twelfth of the dividend yield. Actual dividend payments should ideally have been used, but this information was not available. However, the effect is mitigated by combining the shares into portfolios as per Strugnell et al. (2011). The portfolio returns were then computed as the equally-weighted average of the individual share returns, with equal-weighting utilised rather than value-weighting to reduce the impact of firm specific events, especially if the number of shares in a portfolio is reasonably small (Basiewicz \& Auret, 2009:26).

The three-month Treasury bill was used to measure the risk-free rate, and the FTSE/ JSE All Share Index (ALSI) J203 was used to represent the market portfolio. The dichotomy present in the South Africa market between financial/industrial shares and resources is well-documented in the asset-pricing literature, because these two groupings of shares respond quite differently to market movements. Accordingly, Van Rensburg (2002) advocated the use of an industry-specific market proxy for the two groupings or a two-factor model with a relevant industry factor rather than a composite market portfolio such as the ALSI, which combines the effects of the two groups of shares. To allow for this, Van Rensburg and Robertson (2003), Strugnell et al. (2011) and Ward and Muller (2012) conducted a second analysis to account for these differences. The best way to do this in this study was to form a second smaller sample consisting of only financial and industrial shares, with the FTSE/JSE Financials and Industrials Index (FINDI) J250 used as the market proxy. 
Portfolios rather than individual shares are usually used in asset-pricing tests, because this assists in mitigating the effects of errors associated with estimating betas for individual shares, which is compounded by the fact that shares tend to be quite volatile over time. Forming portfolios necessitates specifying a rule by which to allocate shares to the portfolios. The key criterion in this regard is to ensure a wide dispersion in beta values across the portfolios to overcome the disadvantage of grouping, which tends to contract the range of beta estimates. In this regard, numerous variables were used, such as historical betas, size, the B/M ratio and industry classifications. The latter approach was adopted because it avoids the problem associated with using the B/M ratio or size, as when portfolios are formed based on a sorting variable that has been identified as having a high correlation with share returns (and hence pricing errors) it increases the probability of a type I error - rejecting the null hypothesis when it is actually true (Lo \& MacKinlay, 1990:445-446).

The question of the optimal number of portfolios to form is also a much-debated topic in the literature. Black et al. (1972:86) state that "the choice of the number of portfolios is somewhat arbitrary", with numbers ranging from 10 to 100 being utilised. However, the choice comes down to a trade-off between too few shares in a portfolio and so increasing the effect of firm-specific events and achieving an adequate dispersion in beta values. 20 portfolios was considered optimal. During the time period considered, the JSE changed its industry classification method, resulting in the unbundling of sectors and the creation of new sectors and sub-sectors, whilst some pre-existing sectors were consolidated. Accordingly, it was difficult to utilise an existing industry classification system, and thus a combination of the existing and preceding systems were used, as shown in TABLE l. The allocations were reviewed each year to account for any changes in company focus which may have occurred. For the sample of financial and industrial shares, the five resource-based portfolios $(7,8,9,17$ and 20$)$ were removed from the analysis, resulting in 15 portfolios.

\section{TABLE 1: Industry Portfolios}

\begin{tabular}{llll}
\hline 1 & Technology and Electronics & 11 & Industrial Engineering \\
\hline 2 & Other Industrial & 12 & Building and Construction \\
\hline 3 & Banks and Financial Services & 13 & Insurance \\
4 & Property and Real Estate & 14 & Industrial Transportation \\
\hline 5 & Retail & 15 & Travel and Leisure \\
6 & Food \& Beverages & 16 & Media \\
7 & General Mining & 17 & Chemicals, Oil and Gas \\
\hline 8 & Platinum, Diamond, Coal and Other Precious Metals & 18 & Health Care \\
9 & Gold Mining & 19 & Automobiles and Parts \\
10 & Personal and Household Goods & 20 & Basic Resources \\
\hline
\end{tabular}

Source: Author's allocations

The one limitation of using the industry classification system rather than a financial variable, is that the shares cannot be equally split across the portfolios, and thus the number of shares in each portfolio do vary quite substantially. Compounding this issue is the decline in the number 
of shares in the sample as discussed previously. FIGURE 2 documents the trends in this regard, showing the minimum, maximum and average number of shares in each portfolio over the 15year period, with the numbers on the horizontal axis corresponding to the numbers assigned to each portfolio in TABLE 1. Portfolio 20 (basic resources) had the fewest shares in any one year, with five; while the technology and electronics portfolio had the largest number at 78 . Interestingly, the technology and electronics and banks and financial services portfolios were the most affected by the fall in the number of shares listed on the JSE.

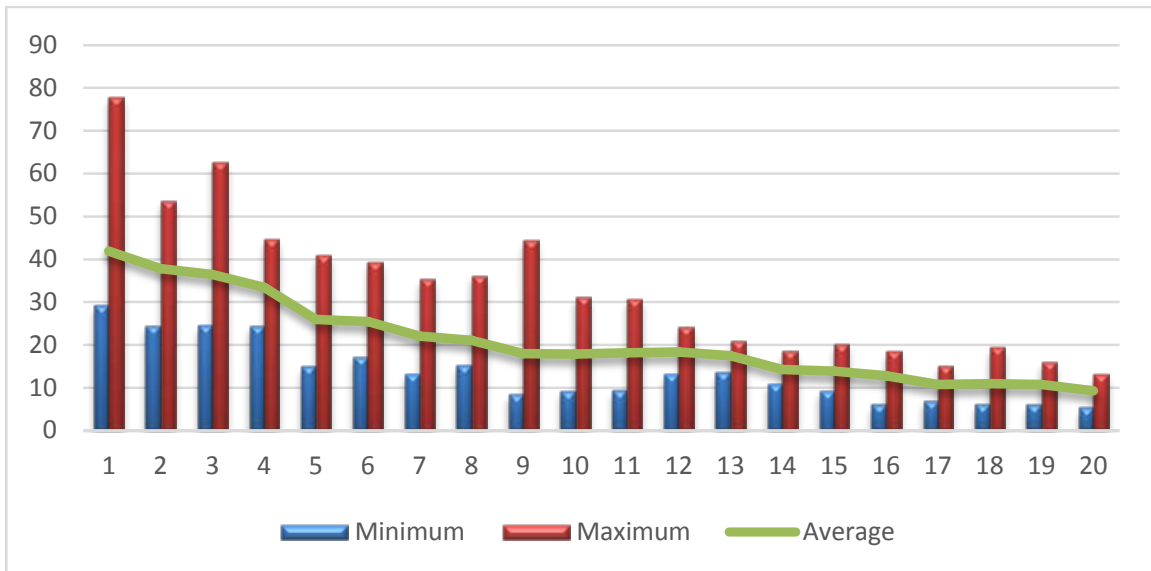

FIGURE 2: Minimum and Maximum Number of Shares in Each Portfolio

Source: own calculations

\section{RESULTS AND ANALYSIS}

\subsection{The CAPM}

The CAPM was estimated using the FM and panel regression approaches for the whole sample and the financial and industrial shares. The coefficients estimated for this model are discussed below in conjunction with a review of the explanatory power of the model. This analysis thus provides a foundation on which the conditional risk-return relationship and the dual-beta model can be compared in the following sections.

The results for the CAPM are displayed in TABLE 2. The intercept estimates are all significant, which suggests that the risk-free rate proxy does not provide a close approximation of the minimum return required by investors. This finding mirrors the major international studies and may not necessarily reflect the use of an inappropriate risk-free rate surrogate, but rather the failure to employ a market portfolio which is mean-variance efficient. Based on the whole sample, the slope coefficients are negative, suggesting the existence of a negative risk premium - the higher the risk, the lower the return. This observation contradicts the theory of a positive risk-return relationship, but mirrors the findings of Van Rensburg and Robertson (2003a), Strugnell et al. (2011) and Ward and Muller (2012). For the sample of financial and industrial shares only, the market risk premium is positive although insignificant. Thus this study confirms the unsuitability of the CAPM in explaining the return-generating process of JSE-listed shares. 
The low $R^{2}$ figures confirm that the model is able to explain only a small proportion of the variation in the returns of the industry portfolios.

TABLE 2: Coefficient Estimates for the CAPM

\begin{tabular}{lccc}
\hline & $\boldsymbol{\gamma}_{\mathbf{0}}$ & $\boldsymbol{\gamma}_{\mathbf{1}}$ & Adjusted $^{2}$ \\
\hline FM Approach & $1.3886 \star \star$ & -0.6009 & $12 \%$ \\
(Whole sample) & $(0.6942)$ & $(1.1756)$ & \\
Panel Approach & $1.5299 \star \star \star$ & $-0.8881 \star \star \star$ & $19 \%$ \\
(Whole sample) & $(0.0583)$ & $(0.1053)$ & \\
FM Approach & 0.7308 & 0.1117 & $11 \%$ \\
(Financial \& Industrial shares) & $(0.8441)$ & $(1.3714)$ & $13 \%$ \\
Panel Approach & $0.6803 \star \star \star$ & 0.2400 & \\
(Financial \& Industrial shares) & $(0.1598)$ & $(0.2596)$ & \\
\hline
\end{tabular}

Source: own calculations

$\star, \star *, * * *$ indicates significance at 10,5 and $1 \%$; standard errors shown in brackets.

\subsection{The Conditional Risk-Return Relationship}

The second model tested was the conditional risk-return relationship that is implied by the CAPM when realised returns rather than expected returns are utilised. Limberis (2012) has reviewed this relationship in the South African market, but one of the goals of this study is to assess the veracity of his findings, especially in light of the fact that they do not conform to international evidence.

The results are displayed in TABLE 3 and reveal that although the FM and panel approaches yield coefficients of differing magnitudes, the signs are identical. Similarly to the results for the traditional model, the intercepts are significant, which defies theory. Pettengill et al. (1995) do not report the intercept estimates from their regressions, and thus while their model holds in terms of the appropriate signs of the slope coefficients, the significance or otherwise of the intercept is not assessed. With regard to the signs of the slope coefficients for the entire sample, $\gamma_{2}$ conforms to theory (based on the panel regression where the estimate is significant), suggesting that in market downturns returns and beta are negatively related. However, the sign of $\gamma_{1}$ is negative, thus still revealing the existence of a negative risk premium in bull markets. This finding contradicts international studies, where a positive relationship between risk and return is identified in bull markets and clearly reveals the inability of a conditional beta to explain returns in South Africa. However, using the contracted sample of financial and industrial shares only, the signs of $\gamma_{1}$ and $\gamma_{2}$ conform to theory and these coefficients are significant at the $10 \%$ level. If the conditional CAPM holds, the estimates of the bull and bear market premiums should be approximately equal in magnitude, although opposite in sign. This was tested using a Wald test, and the F-statistic of 0.0137 meant that the hypothesis could not be rejected. Thus, in contrast to some emerging market evidence, for financial and industrial shares only in the South African market, the up- and down-market risk premiums are reasonably symmetrical. Therefore there is evidence to suggest that the conditional CAPM does hold when 
the market portfolio proxy is adjusted for segmentation in the South African market. However, the adjusted $R^{2}$ figures are still low and the risk premiums are only just significant.

TABLE 3: Coefficient Estimates for the Conditional CAPM

\begin{tabular}{lcccc}
\hline & $\boldsymbol{\gamma}_{\mathbf{0}}$ & $\boldsymbol{\gamma}_{\mathbf{1}}$ & $\boldsymbol{\gamma}_{\mathbf{2}}$ & ${\text { Adjusted } R^{2}}$ \\
\hline FM Approach & $1.3887 \star \star$ & -0.5689 & -0.4892 & $11 \%$ \\
(Whole sample) & $(0.6942)$ & $(1.2083)$ & $(1.1883)$ & \\
Panel Approach & $1.5305 \star \star \star$ & $-0.9344 \star \star \star$ & $-0.8356 \star \star \star$ & $17 \%$ \\
(Whole sample) & $(0.05823)$ & $(0.1114)$ & $(0.1131)$ & \\
FM Approach & 0.7308 & 0.1461 & -0.0583 & $13 \%$ \\
(Financial \& Industrial shares) & $(0.8441)$ & $(1.4399)$ & $(1.2650)$ & \\
Panel Approach & $0.7715 \star \star \star$ & $0.3608 *$ & $-0.3192 *$ & $19 \%$ \\
(Financial \& Industrial shares) & $(0.1119)$ & $(0.1852)$ & $(0.1853)$ & \\
\hline
\end{tabular}

\section{Source: own calculations}

$\star, \star \star, \star * \star$ indicates significance at 10,5 and $1 \%$; standard errors shown in brackets.

Comparing the results of this study based on the whole sample to those of Limberis (2012), who makes no adjustment for market segmentation, there are notable differences. Firstly, he finds a positive, although insignificant, relationship between beta and returns before adjusting for market conditions, whereas a negative relationship is observed in this study, in accordance with other previous work in this area. Secondly, after adjusting for market conditions, he finds a positive risk premium in both up and down markets; whereas a negative premium is obtained in this study.

\subsection{The Dual-Beta CAPM}

The dual-beta CAPM was also estimated using the FM and panel approaches to compare against the CAPM and conditional risk-return relationship so as to assess which specification best describes the risk-return relationship of JSE-listed shares. Prior to the estimation of the crosssectional regressions for the dual-beta CAPM, the time-series estimates of the betas of the portfolios were considered, with the averages displayed in FIGURE 3.

For the whole sample, the down-market betas are larger than the up-market betas on average, as seen in Panel A of FIGURE 3, and this difference is significant (t-statistic of 3.5335). This relationship holds true for 14 of the 20 portfolios (with ten individually significant) and reveals that these portfolios are more sensitive to downturns in the market than upturns. This result mirrors that of Faff (2001) for Australian shares, while Howton and Peterson (1998) found that the reverse is true for the US. The similarity in the findings of this study and the Australian study, and the contrast of these to the US analysis may reflect the difference in sorting procedures used, as the study of Howton and Peterson (1998) classified shares on the basis of size and value compared to the industry affiliations employed in this study and that of Faff (2001). 

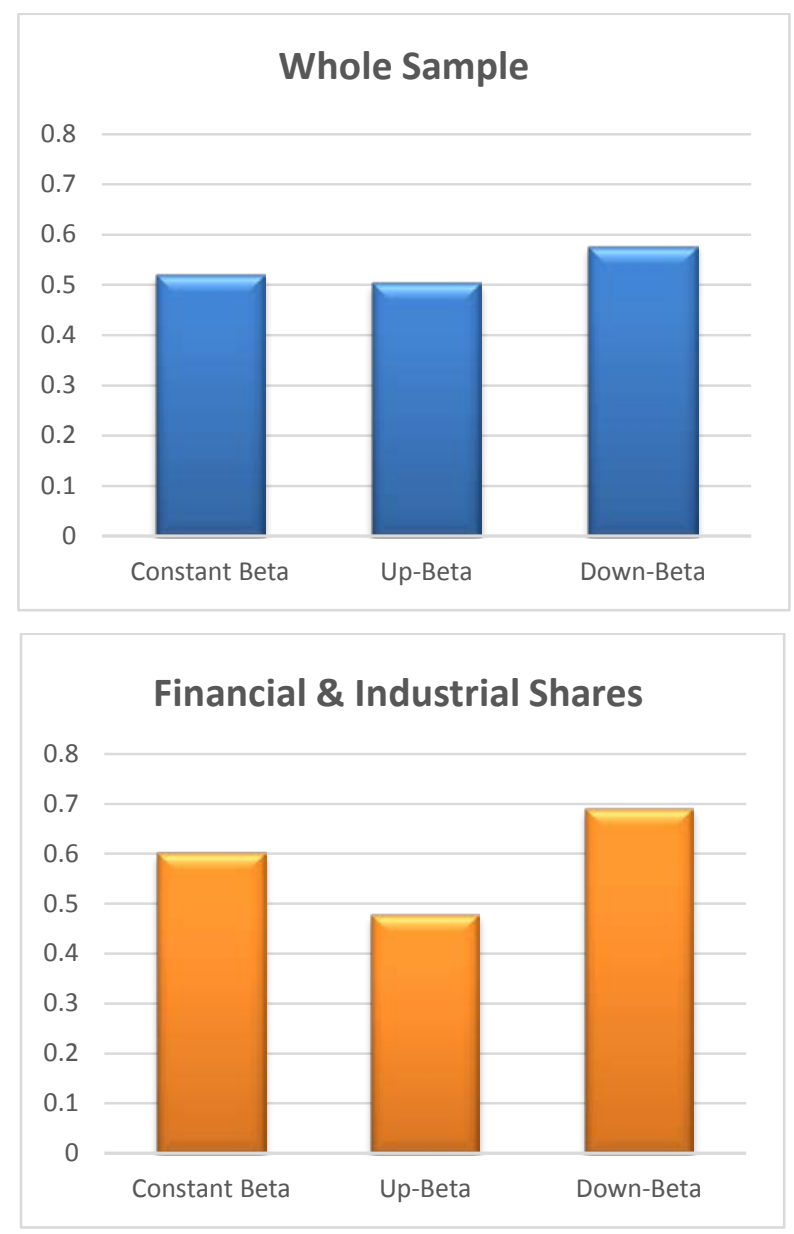

\section{FIGURE 3: Beta Comparisons}

\section{Source: owncalculations}

It is of value to consider the nature of those portfolios, where the bull-market betas are larger than the bear-market betas. The six portfolios include (differences are significant for four): basic resources; chemicals, oils and gas; general mining; gold mining; platinum, diamonds and coal; and property. As is clearly evident, except for the property portfolio, the others all fall into the broader sector category of resource shares. Thus, this analysis clearly points to the different reaction of resource shares to upturns and downturns in the market compared to industrial and financial shares. That is, resource shares are affected less by market downturns than shares in other categories, as they are influenced to a greater extent by resource prices (e.g. gold), which often are negatively correlated with the market: as markets enter into a downturn, investors turn to gold as a safe haven, thus driving up the price of gold and increasing the profit margin of gold-mining companies. Faff (2001) similarly finds that the resource portfolios have higher upmarket betas than down-market betas compared to the portfolios of financial, industrial and consumption goods, although the differences are not significant. The difference in the property portfolio betas is substantial, but overall the values are reasonably low at 0.11 and 0.33 for the bear and bull markets respectively. This trend is confirmed by examining the betas of the sample 
including only financial and industrial shares (panel B of FIGURE 3) where the average up- and down-market betas are lower and higher respectively. The $t$-statistic confirms that this difference is significant.

The results from the cross-sectional tests of the validity of the dual-beta CAPM are shown in TABLE 4. As with the previous models, the intercept estimates are positive and significant, and again, as with the Petengill et al. (1995) article, the studies of the dual-beta CAPM in a crosssectional framework do not examine the significance of the intercept. The FM slope coefficients have the same signs as those from the panel regression, but are insignificant. In this case, the estimate of $\gamma_{1}$ is also insignificant in the panel regression, suggesting that it does not differ from zero over the period examined. In contrast, $\gamma_{2}$ is significantly different from zero in the panel regression. In terms of the model estimated, an insignificant value for $\gamma_{1}$ indicates that there is no positive risk premium during bull markets, while the significant negative coefficient on the down-market beta indicates that there is a substantial negative risk premium in bear markets.

TABLE 4: Coefficient Estimates for the Dual-Beta CAPM

\begin{tabular}{lcccc}
\hline & $\boldsymbol{\gamma}_{\mathbf{0}}$ & $\boldsymbol{\gamma}_{\mathbf{1}}$ & $\boldsymbol{\gamma}_{\mathbf{2}}$ & Adjusted $\boldsymbol{R}^{2}$ \\
\hline FM Approach & $1.3303 \star \star$ & -0.0011 & -0.4915 & $14 \%$ \\
(Whole sample) & $(0.6185)$ & $(0.8777)$ & $(0.7370)$ & \\
Panel Approach & $1.1314 \star \star \star$ & -0.01514 & $-0.1821 \star \star \star$ & $33 \%$ \\
(Whole sample) & $(0.0555)$ & $(0.0774)$ & $(0.05840)$ & \\
FM Approach & $1.0488 \star$ & 0.5087 & -0.5866 & $21 \%$ \\
(Financial \& Industrial shares) & $(0.6961)$ & $(0.7587)$ & $(0.6636)$ & \\
Panel Analysis & $0.8569 \star \star \star$ & $0.5235 \star \star \star$ & $-0.3031 \star \star \star$ & $67 \%$ \\
(Financial \& Industrial shares) & $(0.0726)$ & $(0.0765)$ & $(0.0743)$ & \\
\hline
\end{tabular}

\section{Source: own calculations}

$\star, \star \star, \star \star *$ indicates significance at 10,5 and $1 \%$; standard errors shown in brackets.

For the sample of financial and industrial shares, both slope coefficients are significant and the signs conform to theory: there is a positive risk-return relationship during bull markets and a negative relationship during bear markets. A Wald test was conducted to ascertain whether the risk premiums were approximately equal in sign but opposite in magnitude. This hypothesis could not be rejected at any of the conventional significance levels. Thus, this evidence for the financial and industrial shares conforms to some of the international studies, where a positive risk premium is identified in up markets and the opposite for down markets, provided an adjustment is made for market segmentation. In contrast to Pettengill et al. (2002), who found that dual-betas were not a necessary condition to find a significant relationship between risk and return (only the adjustment for up-and down-market risk premiums), in the South African market this is necessary.

The success of the dual-beta model in the sample of financial and industrial shares is confirmed by a high adjusted $R^{2}$, indicating that the two beta estimates are able to account for more than two-thirds of the variation in the returns across the industry portfolios. Using the whole sample, this model still improves upon both the traditional CAPM and the conditional relation in terms of 
explaining the return-generating process of JSE-listed shares. In the dual-beta model based on the financial and industrial shares, the differences in betas were found to be significant, and the risk premiums were significant for both beta factors, suggesting that the idea of time-varying risk premiums may be the future of asset pricing as various attempts are made to fill the void left by the failure of the CAPM to explain the return-generating process of South African shares.

\section{CONCLUSION}

The CAPM remains the tool most commonly used by South African firms to estimate the cost of equity, yet its empirical failings are well-documented in the literature both internationally and more specifically in the South African market. Therefore, as intimated by Strugnell et al. (2011), there is a desperate need to fill the void of a suitable asset-pricing model for use in both research and practice. In this regard, the purpose of this paper was to assess whether the conditional relationship between risk and return or the dual-beta CAPM provides a better means to evaluate returns than the CAPM.

The conditional relationship between risk and return was found to be unsuitable using the entire sample; however, when the analysis was adjusted for market segmentation, a positive relationship between risk and return was identified during bull markets and a negative relation in bear markets. The risk premiums were approximately equal in magnitude, as predicted by theory. The coefficients were however only significant at the $10 \%$ level, and the adjusted $R^{2}$ of the regression remained low.

The dual-beta model was also considered, as this allows not only for varying risk premiums under different market conditions, but varying betas. The analysis revealed that the up-market betas were lower on average than the down-market betas for financial and industrial shares, while the reverse was true for resource shares. Thus resource shares are less sensitive to market downturns than shares in other sectors. Tests of the model based on the entire sample, again, did not provide sufficient support in favour of the dual-beta specification; however, based on the financial and industrials sample, the estimated coefficients were significant, and the expected sign and the adjusted $R^{2}$ of the model was high.

One possible extension to this research is to consider the ability of the dual-beta CAPM to explain the returns across portfolios formed on the basis of size and B/M ratios. A suitable asset-pricing model must be able to explain all patterns in the data. In addition to this, the dual-beta model estimated in this study is a crude estimate, as the bull and bear markets are determined simply by the sign of the excess market return; however, a more accurate approach would be to allow for a continuously changing time-varying parameter as per Woodward and Anderson (2009).

This research, therefore, has provided greater insight into the asset-pricing dilemma facing financial economists in South Africa, most notably the importance of allowing for time-varying beta estimates. The dual-beta model is a significant improvement on the traditional CAPM for financial and industrial shares, and until further research is conducted to identify a more appropriate model, it offers practitioners an easy and intuitive model to utilise. 


\section{LIST OF REFERENCES}

Asteriou, D. \& Hall, S. (2011). Applied Econometrics, $2^{\text {nd }}$ edition. Hampshire: Palgrave-MacMillan. Banz, R. (1981). The relationship between returns and market value of common stocks. Journal of Financial Economics, 9(1), pp. 3-18.

Basiewicz, P. \& Auret, C. (2009). Another look at the cross-section of average returns on the JSE. Investment Analysts Journal, 69, pp. 23-38.

Basiewicz, P. \& Auret, C. (2010). Feasibility of the Fama and French three factor model in explaining returns on the JSE. Investment Analysts Journal, 71, pp. 13-25.

Basu, S. (1977). Investment performance of common stocks in relation to their price-earnings ratios: A test of the efficient market hypothesis. Journal of Finance, 12(3), pp. 129-156.

Black, F., Jensen, M. \& Scholes, M. (1972). The Capital Asset Pricing Model: Some empirical tests. In Jensen, M. (ed.) Studies in the Theory of Capital Markets. New York: Praegar (pp. 79-124).

Bhaduri, S. \& Durai, S. (2006). Asymmetric beta in bull and bear market conditions: Evidence from India. Applied Financial Economic Letters, 2(1), pp. 55-59.

Bhardwaj, R. \& Brooks, L. (1993). Dual-betas from bull and bear markets: Reversal of the size effect. Journal of Financial Research, 16(4), pp. 269-284.

Choi, D. \& Fu, T. (2005). The dual-beta model: Evidence from the New Zealand stock market. In Zerger, A. and Argent, R. (eds) MODSIM 2005 International Congress on Modelling and Simulation. Modelling and Simulation Society of Australia and New Zealand, December 2005, pp. 566-572.

Correia, C. \& Cramer, P. (2008). An analysis of cost of capital, capital structure and capital budgeting practices: A survey of South African listed companies. Meditari Accountancy Research, 16(2), pp. 3152.

Elsas, R., દl Shaer, M. \& Theissen, દ. (2003). Beta and returns revisited: Evidence from the German Stock Market. Journal of International Financial Markets, Institutions \& Money, 13(1), pp. 1-18.

Esterer, F. \& Shroder, D. (2011). The implied equity duration: Empirical evidence for explaining the value premium. University of London, London (Working paper).

Estrada, J. (2000). The cost of equity in emerging markets: a downside risk approach. Emerging Markets Quarterly, 4, pp. 19-30.

Fabozzi, F. \& Francis, J. (1977). Stability tests for alphas and betas over bull and bear market conditions. Journal of Finance, 32(4), pp. 1093-1099.

Faff, R. (2001). A multivariate test of a dual beta CAPM: Australian evidence. Financial Review, 36, pp. 157-174.

Fama, દ. \& French, K. (1992). The cross-section of expected stock returns. Journal of Finance, 47(2), pp. $427-465$.

Fama, \&. \& French, K. (1993). Common risk factors in the returns on stocks and bonds. Journal of Financial Economics, 33(1), pp. 3-56.

Fama, E. \& MacBeth, J. (1973). Risk, return and equilibrium: Empirical tests. Journal of Political Economy, 81(3), pp. 607-636. 
Fletcher, J. (1997). An examination of the cross-sectional relationship of beta and return: UK evidence. Journal of Economics and Business, 49, pp. 211-221.

Fletcher, J. (2000). On the conditional relationship between beta and return in international stock returns. International Review of Financial Analysis, 9, pp. 235-245.

Haugen, R. \& Baker, N. (1996). Commonality in the determinants of expected stock returns. Journal of Financial Economics, 41(3), pp. 401-439.

Ho, Y-W., Strange, R. \& Piesse, J. (2006). On the conditional pricing effects of beta, size, and bookto-market equity in the Hong Kong market. Journal of International Financial Markets, Institutions and Money, 16, pp. 199-214.

Hodoshima, J., Gar-za-Gómez, X \& Kunimura, M. (2000). Cross-sectional regression analysis of return and beta in Japan. Journal of Economics and Business, 52, pp. 515-533.

Howton, S. \& Peterson, D. (1998). An examination of cross-sectional realised stock returns using a varying-risk beta model. Financial Review, 33, pp. 199-212.

Lam, K. (2001). The conditional relation between beta and returns in the Hong Kong stock market. Applied Financial Economics, 11, pp. 669-680.

Limberis, A. (2012). An empirical investigation of the conditional risk-return trade-off in South Africa. Unpublished M-Com (Accountancy) thesis. Johannesburg: University of Witwatersrand.

Lo, A. \& Mackinlay, C. (1990). Data-snooping biases in tests of financial asset pricing models. Review of Financial Studies, 3(3), pp. 461-467.

Morelli, D. (2007). Beta, size, book-to-market equity and returns: A study based on UK data. Journal of Multinational Financial Management, 17(3), pp. 257-272.

Pettengill, G., Sundaram, S. \& Mathur, I. (1995). The conditional relation between beta and returns. Journal of Financial and Puantitative Analysis, 30(1), pp. 100-116.

Pettengill, G., Sundaram, S. \& Mathur, I. (2002). Payment for risk: Constant beta vs. dual-beta models. The Financial Review, 37 (2), pp. 123-136.

Sandoval, \&. \& Saens, R. (2004). The conditional relationship between portfolio beta and and returns: Evidence from Latin America. Cuadernos de Economía, 4l, pp. 65-89.

Sollis, R. (2012). Empirical Finance for Finance and Banking. Cornwall: John Wiley \& Sons.

Suntraruk, P. (2008). A simple test of the CAPM model in bull and bear market conditions: The case of Thailand. AU Journal of Management, 6(1), pp. 62-70.

Strugnell, D., Gilbert, E. \& Kruger, R. (2011). Beta, size and value effects on the JSE, 1994-2007. Investment Analysts Journal, 74, pp. 1-17.

Van Rensburg, P. (2002). Market Segmentation on the Johannesburg Stock Exchange II. Journal of Studies in Economics and Econometrics, 26(1), pp. 83-100.

Van Rensburg, P. \& Robertson, M. (2003). Size, price-to-earnings and beta on the JSE securities exchange. Investment Analysts Journal, 58, pp. 7-16.

Vosilov, R. \& Bergstrom, B. (2010). Cross-section of stock returns: Conditional versus unconditional and single-factor versus multifactor models. Umea School of Business, Sweden (Working paper). 


\section{Charteris}

Woodward, G. \& Anderson, H. (2009). Does beta react to market conditions? Estimates of bull and bear betas using a nonlinear market model with endogenous threshold parameters. Quantitative Finance, 9(8), pp. $913-924$.

Ward, M. \& Muller, C. (2012). Empirical testing of the CAPM on the JSE. Investment Analysts Journal, 76, pp. 1-12.

World Federation of Exchanges (2013). Annual Statistics South Africa, Equity Markets. [Online]

Available: http://www.world-exchanges.org/statistics/annual-query-tool. (Accessed: 26 July 2013).

Zhang, J. \& Wilborg, C. (2010). CAPM in up and down markets: Evidence from Six European emerging markets. Journal of Emerging Market Finance, 9(2), pp. 229-255. 